\title{
EVALUATING GLOBAL MUNICIPAL SOLID WASTE MANAGEMENT EFFICIENCY FROM A CIRCULAR ECONOMY POINT OF VIEW
}

\author{
ELENA CRISTINA RADA ${ }^{1}$, ATHANASIA TOLKOU ${ }^{2}$, IOANNIS KATSOYIANNIS ${ }^{2}$, ELENA MAGARIL ${ }^{3}$, \\ ANDREY KISELEV ${ }^{3}$, FABIO CONTI ${ }^{1}$, MARCO SCHIAVON $^{4} \&$ VINCENZO TORRETTA $^{1}$ \\ ${ }^{1}$ Department of Theoretical and Applied Sciences, University of Insubria, Italy \\ ${ }^{2}$ Laboratory of Chemical and Environmental Technology, Department of Chemistry, \\ Aristotle University of Thessaloniki, Greece \\ ${ }^{3}$ Department of Environmental Economics, Ural Federal University, Russian Federation \\ ${ }^{4}$ Department of Civil, Environmental and Mechanical Engineering, University of Trento, Italy
}

\begin{abstract}
The Circular Economy (CE) principles recently set out by the European Union (EU) include additional guidelines for municipal solid waste (MSW) management. More detailed information about material streams must be generated and managed so that the entire system can be monitored from a new perspective. Suitable indicators (and indices from them) must be made readily available, so that they can be used to assess the efficiency that the European Union expects from the sector. This article presents a preliminary critical analysis of the literature and identifies that indicators and indices should be considered to facilitate the evaluation of MSW management under a CE vision. The analysis is combined with a discussion of the situation in various countries, to provide an overview of attempts to implement CE strategies worldwide. Special waste is not dealt with in this article as EU updated the vision of waste management starting from the MSW sector, on which this work is focused.
\end{abstract}

Keywords: sustainability, circular economy, recycling, integrated waste management, selective collection, quality index.

\section{INTRODUCTION}

Municipal solid waste (MSW) management in the European Union (EU) is based on wellknown principles that include recycling aimed to material recovery as a strategic option [1]. This presents major challenges to most cities in the modern world [2]-[4]. In many countries, especially in developing countries and emerging economies, MSW management models are generally insufficient, with incomplete waste collection coverage and low rates of source-separation and recovery of waste streams, which end up in landfills or dumps [5]-[10]. These final destination sites can cause significant environmental and health impacts: fugitive emissions of biogas play a role in the greenhouse gas balances (globally) and in the odour impact (locally); the leachate generated through waste leaching is difficult to treat; waste pickers working on informal sites inhale pollutants. Thus, improved solid waste management strategies are required worldwide, because this problem will be aggravated in the coming years due to the increased production of MSW. Sustainable development goals (SDGs) - the blueprint of relevant global issues adopted by the UN, has a strong connection with efficient MSW management, and the transition towards Circular Economy can be the major principle for implementation. The CE principles, recently drafted by the EU, address this problem, and give specific attention to material recovery and reuse [11]-[14]. In addition to recyclable materials, the transformation of waste with high calorific value into energy is an option identified in the new EU Green Deal, but may at first sight appear to be controversial; in reality, thermochemical waste-to-energy (WtE) plants allow for energy recovery and their environmental impact can be managed 
adequately only through enhanced expertise. What is clear is that, through energy recovery, landfilling can be reduced significantly not only in mass but also in volume [15]-[17]. The environmental impact cannot be compared to extreme source separation methods (e.g., metals) because of the complex behaviour of some substances in the thermal process (e.g., the percentage of metals in the ash and the stack). However, processing source separated waste needs optimized approaches for avoiding local impact too (an example is composting). The advantages of $\mathrm{CE}$ from this perspective therefore require specific analysis.

Fig. 1 illustrates the waste management hierarchy from the most desirable (prevention) to the least desirable (disposal) options. Prevention is the most effective way of dealing with waste as it reduces the amount generated in the first place, thus reducing the impact on the environment and the cost, as a lower amount of waste needs managing.
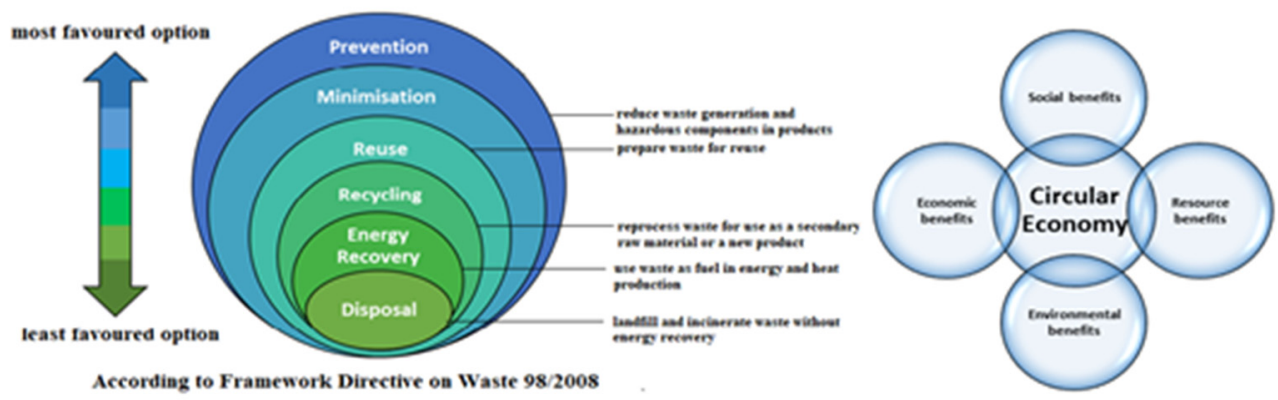

Figure 1: Municipal solid waste management hierarchy.

Disposal does not extract any value and includes landfill and incineration, which offer no energy recovery in their most simplified versions. It is at the bottom of the hierarchy because the materials become useless and have no value when they are sent to landfill (when no pre-treatment is implemented), and so ideally this would only be a last option. Unfortunately, worldwide, many towns and cities are not able to follow the waste hierarchy and the only option they consider is disposal. Generally, specifically in low-income countries, most of the waste is never collected (it is dumped or burned) and even when it is, most of it is taken to landfill [18]. However, these locations are still expected to move towards a $\mathrm{CE}$ management approach. The transition towards a $\mathrm{CE}$ can be encouraged through a combination of regulations and incentives [19].

Concerns have been raised about the adequacy of the methodology currently used to analyse the composition of residual MSW, which is the waste stream containing unsorted materials. The presence of recyclable materials that have not been separated at the source must be assessed. For example, in the Italian Trentino Province, where such analyses are conducted, although 29 fractions are used in the characterization, modifications are necessary due to the requirements arising from CE principles [20]. In general, the following classes of materials among the residual MSW should constitute the minimum level of analysis:

- $\quad$ Plastics: plastic packaging waste, PET bottles and HDPE bottles.

- Cellulose-based items: paper packaging waste and similar.

- Glass: glass packaging waste. 
- Aluminium: aluminium packaging waste, similar classes and aluminium packaging accessories.

- Steel: steel packaging waste and similar classes.

- The organic proportion of MSW (OFMSW): the percentage (weight) of organic material among the residual MSW should be assessed, both for the OFMSW and for green waste.

Thus, the kind of information that should be collected represents the amount and quality of the valuable material present in the residual MSW. Concerning the characteristics of the above presented list of classes of materials, the sector of MSW management evolved strongly: in order to generate a detailed characterization of residual MSW aimed to check the $\mathrm{CE}$ potentialities in the related territory, in some cases the list has been expanded up to more than 20 fractions.

The availability in the literature of indicators and indices that are suitable for considering the EU vision of $\mathrm{CE}$ is another issue that must be addressed. This article provides initial comments about the conventional indicators and indices available in MSW management, and considerations about the characteristics that these indices should have to address the new requirements in strong connection with the goal 12 of SGDs. Few studies address the strategies that can be implemented to monitor and improve MSW management from a CE perspective. Thus, we analyse the available indicators and indices and propose those that are suitable for assessing the effectiveness of CE strategies in MSW management. In addition, six international case studies are reviewed to illustrate the situation in different countries and reveal novel options that comply with CE principles.

\section{CONSIDERATIONS ON THE INDICATORS AND INDICES FOR MSW MANAGEMENT IN THE LITERATURE}

Various indicators are available in the MSW management field, which can be used to describe aspects of MSW management. Indicators for the evaluation of MSW collection systems have been proposed, and focus on performance in terms of distance, time and fuel consumption, vehicle and personnel workload, and costs [21]-[24]. In terms of MSW source separation, quantity and quality efficiency indicators for the various classes have been used in many contexts [25]-[29] and studies comparing the recycling processes for the separated materials have been conducted using Life Cycle Assessment (LCA) tools [30][32]. All of the indicators currently available in the literature focus on processing information about the various material flows coming from selective collection (SC), and are aimed at the constant improvement of integrated waste management scenarios. However, only a few studies have considered what improvements could be implemented in the management of residual MSW with respect to the CE principles.

\section{INDICATORS AND INDICES FOR EVALUATION OF CE EFFECTIVENESS}

The brief analysis reported above indicates that an additional effort must be made to obtain information about:

- The efficiency of SC for each material of interest.

- The quality at the source of the separated materials.

- The economic and environmental sustainability of the waste collection system and of the treatments available for the separated sources.

- The destination of the residues in the adopted treatments. 
- Carbon capture and sequestration (CCS) technologies applied to the off gas from energy recovery treatments.

- The development of reuse practices.

The indicators and indices that should be developed (or confirmed) must consider the above listed characteristics. In particular, WtE is not excluded from the scenarios managed according to CE principles: new indicators should acknowledge the implementation of CE practices in residual MSW energy recovery processes regarding bottom ash vitrification and reuse, carbon capture technologies applied to off gas to extract $\mathrm{CO}_{2}$ as an industrial product, exploitation of off gas from energy recovery processes for district heating and metal recovery from slag.

A selective collection quality index (SCQI) has recently been proposed in the international literature to address the $\mathrm{CE}$ vision that includes collection efficiency (and, for each fraction, the type of collection), quality of the source of the separated materials, the presence of a tariff, the influence of tourism [33]. That proposal originated from an Italian case-study. A group of proposed indicators were applied to a specific period to assess the potential of the index. Quantitative results of this case study were obtained, based on the sub-parameters that characterize the proposed index. Decision-makers can then focus on a specific territory and identify the critical SC issues that must be addressed [33]. The SCQI aims at making available an integrated tool that can be used in other areas in Italy and abroad, within the CE context. This limitation depends on the structure of MSW management that is taken into account as a background of the index.

The percentage of thermochemically treated waste with a lower heating value (LHV) higher than a certain threshold, e.g. LHV $>13 \mathrm{MJ} / \mathrm{kg}$, and sent to energy recovery options, can be used as an indicator of the energy recovery management performance of the system. The waste to be considered should be both the one directly used (residual MSW) and the one indirectly used (Solid Recovered Fuel, or SRF) as the input for thermochemical plants. The cited value has been assumed as a decisional threshold in Italy for many years. Indeed, for a long period, waste with $\mathrm{LHV}>13 \mathrm{MJ} / \mathrm{kg}$ had to be sent to energy recovery plants instead to landfills. The residual MSW stream sent to thermochemical plants for energy recovery could be differentiated into sub-streams, depending on the final destination and the pre-treatment adopted (if any). Checking if the threshold value proposed for addressing the energy strategies in the waste sector is under consideration would be strategic in both cases. Administrations that only send waste with LHV $>13 \mathrm{MJ} / \mathrm{kg}$ to thermochemical plants should get a $100 \%$ score in this evaluation. Referring to the MSW directly or indirectly used as an input in thermochemical plants, the percentage of waste with recovered ash (bottom ash and fly-ash) could be another indicator. Bottom ash can potentially be used in the cement industry after treatment (a minimal metal recovery can also be performed by an integrated process). Fly-ash can potentially be vitrified and used as a secondary product. Plants where an integrated vitrification is performed (e.g., gasification at a high temperature, including cases of indirect combustion with a vitrifying chamber) should be given a $100 \%$ score for this indicator. Integrating these concepts can provide an index that is suitable for analysing the role of WtE in the frame of a $\mathrm{CE}$ approach.

In terms of $\mathrm{SC}$ of food waste, one $\mathrm{CE}$ indicator could be the percentage of this stream sent to anaerobic digestion (AD), which gives two final products: biogas and compost. This is preferable to direct composting, since $\mathrm{AD}$ allows for the production of methane, generates less odours and is characterized by higher acceptability by the local population. The biomethane extracted from biogas should guarantee a higher score. If biomethane is produced from $100 \%$ of the food waste available in the territory, a $100 \%$ score should be 
given for this indicator. Scenarios with biogas could be differentiated by considering the application of a $60 \%$ coefficient to reduce the value of the indicator $(60 \%$ can be assumed as the percentage of methane in the biogas). For example, if food waste has a SC rate of $80 \%$, and $50 \%$ is sent to $\mathrm{AD}$ where biogas (and not biomethane) is produced, the indicator would have the following values: $80 \% \cdot 50 \% \cdot 60 \%=0.24$. Integrating these indicators can provide a $\mathrm{CE}$ index. In case of the extraction of $\mathrm{CO}_{2}$ from the off gas that remains after biogas upgrading, the scenario becomes more complex. Here, an aspect to be focused on is the fate of the $\mathrm{CO}_{2}$ : it can be either a product or a compound to be sequestrated. This opportunity (extraction of $\mathrm{CO}_{2}$ ) is not yet widely adopted; however, in order to avoid future recalibration of the indicators and indexes, an overall index could already include this strategy.

Developed and developing countries currently apply different MSW management approaches. The MSW management model for developed countries is focused on the hierarchy of waste management, as reported in Fig. 1 [1]. In developing countries, the model is generally insufficient with incomplete waste collection coverage, and low levels of source-separation and recovery rates of waste, which thus ends up combined and sent to landfills or dumps. Table 1, summarizes the case studies described below for MSW management worldwide.

Table 1: MSW management in the six countries analysed.

\begin{tabular}{|l|l|l|l|}
\cline { 2 - 4 } Case study & Main fraction in MSW & $\begin{array}{l}\text { Emerging/characterising } \\
\text { technology }\end{array}$ & Reference \\
\hline Iran & Organic material & Composting process & {$[34]$} \\
\hline China & Food waste & Incineration & {$[35],[36]$} \\
\hline India & Food and inert MSW & Landfills & {$[37]$} \\
\hline $\begin{array}{l}\text { Czech } \\
\text { Republic }\end{array}$ & Municipal waste landfill & Composting process & {$[38]$} \\
\hline England & $\begin{array}{l}\text { Household waste, food and } \\
\text { textile separation waste }\end{array}$ & Anaerobic digestion & {$[39]$} \\
\hline Russia & Paper & Recycling and landfill & {$[40]$} \\
\hline
\end{tabular}

\subsection{Iran}

MSW management was officially implemented in Iran only in 2004 when the government established the first regulation of solid waste, which became necessary due to the rapid population growth in urban areas [34]. Iran has a per capita MSW production of $272 \mathrm{~kg}$ per year, which has remained almost constant over the past decade. The absence of a specific programme to get a reduction of the production of MSW means that SC is only conducted in some urban areas and citizens lack a proper training in waste separation. The SC collection rate is thus lower than $8 \%$ [34]. Considering the high content of food waste in the residual MSW (more than 68\%) [34], the absence of defined strategies for recycling may lead to significant emissions of greenhouse gases from the waste sector. Esmaeilizadeh et al. [34] proposed a set of strategies that can help Iran take action towards the implementation of CE principles, including investing in education to raise the awareness of the population about the importance of a proper waste management strategy and SC procedures, making waste hierarchy the basic principle for future waste management 
programmes, involving experts in drafting waste management plans and make strategic decisions, and considering cost-benefit analyses during the decision-making processes.

\subsection{China}

China has made efforts to improve the quality of its MSW management system over the last decades. However, recycling is not formally recognized (yet) as an important contributor to MSW management in China. Informal recycling practices are conducted, mainly by waste pickers. The food waste proportion collected in China accounts for about $60 \%$ of the generated MSW [35]. According to Liu et al. [35], the environmental performance of the Chinese MSW management system could be maximized if a minimum of between $20 \%$ and $30 \%$ of food waste were collected separately and treated in $\mathrm{AD}$ or composting facilities, and if the products of anaerobic or aerobic treatments were used in agriculture. Incineration is proposed to be the best process for dealing with residual MSW [35], in spite of its low energy content. Of course, the high population density that characterizes many cities makes incineration more appealing. The risk consists in the possibility that building incinerators before optimizing SC could make citizens less interested in source separation. Shanghai was the first Chinese city to implement SC and a dedicated regulation [36]. According to Xiao et al. [36], the economic policies developed by the local administration will have a major impact on the local management of MSW in the future. The Shanghai model may also positively influence the MSW management of other cities in China and worldwide. The food waste percentage in the residual MSW makes it suitable for a biodrying treatment aimed to SRF production. SRF could be used in cement kilns in order to partially substitute coal with advantages also in terms of $\mathrm{CO}_{2}$ emissions. Indeed, since a fraction of residual MSW is discarded biomass, also SRF is partially renewable. Moreover, the low percentage of SC presently reached makes interesting the option of post-treatment of biodried material for extraction of glass, metals, inert material to be sent into the recycling sector, according to the principles of CE. The scientific literature demonstrates that China is contributing to study the viability of this process, this approach cannot be considered as a characteristic of the Chinese MSW sector yet.

\subsection{India}

Urban areas in India are characterized by high population densities and high expansion rates that lead to several environmental problems, including the management of MSW [37]. Zooming on a region, according to local estimations, about 557,000 t/y of MSW are dumped in public areas in Delhi. A large proportion of the illegally dumped MSW includes biodegradable MSW (425,000 t/y), paper and cardboard $(30,000 \mathrm{t} / \mathrm{y})$ and plastics $(38,000 \mathrm{t} / \mathrm{y})$. High quantities of inert MSW (70-95\%) and food waste (80\%) were identified in various neighbourhoods of the city and represent different socio-economic conditions [37]. Nagpure [37] developed a model to track the characteristics of illegally dumped MSW in selected neighbourhoods (e.g., the spatial frequency of dumping, the waste mass and composition). A comparison of the MSW generated annually in neighbourhoods and that illegally dumped indicates that only $67 \%$ of the MSW generated in poor neighbourhoods is sent to landfills, compared to $97-99 \%$ in higher income neighbourhoods. Besides the dumping problem, India is known for a significant use of anaerobic digesters at village scale. The technology in use is simplified, but biogas is exploited e.g. for the kitchen of local schools. This energy recovery strategy goes in parallel with material recovery because 
the digestate can be applied to agriculture. From this point of view, CE appeared in India before the recent perspectives set by EU.

\subsection{Czech Republic}

In Czech Republic, composting is an important part of the CE implementation and contributes to closing the waste management cycle thanks to the characteristics of its final product. In the case study described by Vaverková et al. [38], the process of composting of food waste is conducted on the surface of a reclaimed landfill site. However, bad composting design or inappropriate management of the composting process could lead to the growth of invasive and undesired plant species. Through a monitoring campaign, 88 plant species were found in various phases of composting. Specific expedients such as the occurrence of the thermophilic phase and sufficient moisture can help preventing the development of invasive weeds. The composting of food waste produced locally should also be considered to avoid the possible presence of the seeds of allochthonous species. Apart from these specific problems, often potential, composting is seen favourably in term of CE in spite of the difficulties of local acceptance. Such difficulties are related to the generation of odours that cannot be easily managed in large plants.

\subsection{England}

In England, MSW comprises both household waste and waste generated by industry, commercial activities and institutional bodies, provided that the characteristics of the waste produced in non-household contexts are similar to household waste. However, in Nottingham [39] only household waste is regarded as MSW. The authors proposed five indicators that consider the waste management hierarchy: the per capita waste generation, the recycling rate, the SC rate, the recovery rate and the rate of landfilling. Waste prevention ranks highest on the waste management hierarchy and is regarded as the most desirable option for diverting waste from landfill: less waste, less problems. An alternative scenario is proposed that considers food waste and textile separation at the source and the use of AD to treat separately collected organic waste [39].

\subsection{Russia}

Open landfills were for many years the main option for waste management in Russia, but a large-scale reform of waste management is currently being implemented. The problems of managing existing landfills and dumps are being addressed, along with the optimization of management systems for newly generated waste streams, particularly at the collection stage, which will increase the level of processing. The licensing of waste operators has also been introduced, which will enable the best possible technological options to be chosen when planning solid waste management schemes [40]. Another important development is the introduction of renewable materials and technologies into enterprises, in which a transition to circular business models could be implemented by considering CE principles [41]. Ecological regulations have been introduced, and a model of extended producer responsibility has been developed based on the positive experiences of European countries [40], [42]. The identification of realistic scenarios is important and requires environmental and economic assessments. In a study in Irkutsk [43], an environmentally optimal scenario for waste management has been identified that includes the separate collection and processing of recyclable materials in combination with the preliminary aerobic mechanical and biological treatment of residual waste before disposal, but this scenario is not 
economically viable in real conditions. Energy recovery from waste is the most important factor in waste management in Russia, so it is important to investigate different waste flow characteristics [44]. The Russian Industrial development strategy for the processing, treatment and disposal of industrial waste and MSW for the period up to 2030 has defined one of the main CE resource-oriented indicator - the level of substitution (in percentage) of non-renewable natural resources for recycled ones for application in national economics, thus characterizing the scope of $3 R$ (reduce-reuse-recycle) principle in the country [45]. Specific indicators, measuring the share (or rate) of achieved success towards CE, are considered to be the most valuable and all-purpose instrument for the CE ideology transition as it was mentioned by Kiselev et al. [46] for sewage sludge, but relevant for MSW.

The separate collection of waste has not been fully implemented in Russia, so solutions aimed at obtaining useful products and energy from unsorted organic waste deserve attention. In Paukov et al. [47] the processing of organic unsorted solid waste is proposed by coking them together with oil residues to obtain liquid oil products. Such an approach would enable organic MSW (waste tires, plastic, etc.) to be processed in oil refineries instead of building specialized waste processing plants. The region of Sverdlovskaya Oblast has been recently analysed from the perspective of CE strategies. Although the recovery of materials from MSW was lower than $15 \%$ before 2017 [48], this region is considering CE, and involves the contribution of the university sector [49].

Training is extremely important and is a priority in the context of waste management reform, as production and consumption waste management is a very specific area that requires interdisciplinary knowledge. The education system must also quickly respond to the demands of economic development and the prospect of a transition to a new "circular" model. The approach to learning therefore urgently requires changing. Experiences of implementing educational programs focused on waste management are currently limited in Russia, and this issue should be addressed at the regional level. Universities can educate future managers, define new management approaches, develop new technologies for recycling/recovery, and disseminate the principles of $\mathrm{CE}$ through the student community.

\section{CONCLUSIONS}

The majority of the indicators available focus on the valuable sources derived from the separate collection systems. These indicators are useful for assessing a particular system or process, but to put things in perspective and to identify better methods for increasing sustainability more broadly, improvements are required. Specifically, the characteristics of the indicators and indices should consider CE practices, and new indicators should be developed, which focus for example on residual MSW analyses, treatment residues valorisation, reuse practices, CCS technologies, green energy production (including biofuels) and sustainability of the MSW management system as a whole. A problem of the adoption of these indicators in low-income regions is related to the incomplete collection of waste and, more in general, to the absence of a tradition of data generation in the waste management sector. Reliable data generation is compulsory to take advantage of the potential of the indicators and indices.

\section{ACKNOWLEDGEMENT}

This research was supported by Act 211 Government of the Russian Federation, contract № 02.A03.21.0006.). 


\section{REFERENCES}

[1] Directive 2018/851/EC of 30 May 2018 amending directive 2008/98/EC on waste. Official Journal of the European Union. eur-lex.europa.eu/legal-content/en/TXT/ PDF/?uri=CELEX:32018L0851\&from=EN. Accessed on: 5 Dec. 2020.

[2] Deus, R., Bezerra, B. \& Battistelle, R., Solid waste indicators and their implications for management practice. International Journal of Environmental Science and Technology, 16, pp. 1129-1144, 2019.

[3] Challcharoenwattana, A. \& Pharino, C., Multiple-criteria decision analysis to promote recycling activities at different stages of urbanization. Journal of Cleaner Production, 137, pp. 1118-1128, 2016.

[4] Xevgenos, D., Papadaskalopoulou, C., Panaretou, V., Moustakas, K. \& Malamis, D., Success stories for recycling of MSW at municipal level: A review. Waste and Biomass Valorization, 6, pp. 657-684, 2015.

[5] Anh, V.T.L. \& Hung, D.M., Proposal of a combined environmental management solution for municipal solid waste (MSW) separation in a developing country: For pilot realization in, Hanoi, Vietnam. International Journal of Integrated Engineering, 12, pp. 9-13, 2020.

[6] Ibáñez-Forés, V., Bovea, M.D., Coutinho-Nóbrega, C. \& de Medeiros, H.R., Assessing the social performance of municipal solid waste management systems in developing countries: Proposal of indicators and a case study. Ecological Indicators, 98, pp. 164-178, 2019.

[7] Anwar, S., Elagroudy, S., Abdel Razik, M., Gaber, A., Bong, C.P.C. \& Ho, W.S., Optimization of solid waste management in rural villages of developing countries. Clean Technology and Environmental Policy, 20, pp. 489-502, 2018.

[8] Stanisavljevic, N., Levis, J.W. \& Barlaz, M.A., Application of a life cycle model for European Union policy-driven waste management decision making in emerging economies. Journal of Industrial Ecology, 22, pp. 341-355, 2018.

[9] Ferronato, N., Torretta, V., Ragazzi, M. \& Rada, E.C., Waste mismanagement in developing countries: A case study of environmental contamination. UPB Scientific Bulletin Series D, 79, pp. 185-196, 2017.

[10] Bing, X., Bloemhof, J.M., Ramos, T.R.P., Barbosa-Povoa, A.P., Wong, C.Y. \& van der Vorst, J.G.A.J., Research challenges in municipal solid waste logistics management. Waste Management, 48, pp. 584-592, 2015.

[11] Purnell, P., Velenturf, A.P.M. \& Marshall, R., New governance for circular economy: Policy, regulation and market contexts for resource recovery from waste. Green Chemistry, 63, pp. 395-422, 2020.

[12] Savastano, M., Belcastro, M. \& Dentale, F., The role of waste collection centers in a circular economy scenario: An empirical study on the citizens' perception. Environmental Engineering and Management Journal, 18, pp. 2181-2192, 2019.

[13] Fellner, J., Laner, D., Warrings, R., Schustereder, K. \& Lederer, J., Potential impacts of the EU circular economy package on the utilization of secondary resources. Detritus, 2, pp. 16-23, 2018.

[14] Liu, L., Liang, Y., Song, Q. \& Li, J., A review of waste prevention through 3R under the concept of circular economy in China. Journal of Material Cycles and Waste Management, 19, pp. 1314-1323, 2017.

[15] Priyadarshini, P. \& Abhilash, P.C., Circular economy practices within energy and waste management sectors of India: A meta-analysis. Bioresource Technology, 304, $123018,2020$. 
[16] Halkos, G. \& Petrou, K.N., Analysing the energy efficiency of EU member states: The potential of energy recovery from waste in the circular economy. Energies, 12, 3718, 2019.

[17] Rada, E.C., Ragazzi, M., Torretta, V., Castagna, G. \& Adami, L., Circular economy and waste to energy. AIP Conference Proceedings, 1968, 030050, 2018.

[18] Maine's advanced recycling programs succeeding, Natural Resource Council of Maine.

www.nrcm.org/news/maines-advanced-recycling-programs-succeeding/. Accessed on: 23 Nov. 2020.

[19] Velenturf, A.P.M., Purnell, P., Tregent, M., Ferguson, J. \& Holmes, A., Coproducing a vision and approach for the transition towards a circular economy: Perspectives from government partners. Sustainability, 10, 1401, 2018.

[20] Rada, E.C. \& Cioca, L., Optimizing the methodology of characterization of municipal solid waste in EU under a circular economy perspective. Energy Procedia, 119, pp. 72-85, 2017.

[21] Bertanza, G., Ziliani, E. \& Menoni, L., Techno-economic performance indicators of municipal solid waste collection strategies. Waste Management, 74, pp. 86-97, 2018.

[22] Teixeira, C.A., Avelino, C., Ferreira, F. \& Bentes, I., Statistical analysis in MSW collection performance assessment. Waste Management, 34, pp. 1584-1594, 2014.

[23] Hemidat, S., Oelgemöller, D., Nassour, A. \& Nelles, M., Evaluation of key indicators of waste collection via GIS techniques as a planning and control tool for route optimization. Proceedings of the 6th International Conference on Environmental Technology and Knowledge Transfer, pp. 165-176, 2016.

[24] Bringhenti, J.R., Zandonade, E. \& Günther, W.M.R., Selection and validation of indicators for programs selective collection evaluation with social inclusion. Resources Conservation \& Recycling, 55, pp. 876-884, 2011.

[25] López, I., Gutiérrez, V., Collantes, F., Gil, D., Revilla, R. \& Gil, J.L., Developing an indicators plan and software for evaluating street cleanliness and waste collection services. Journal of Urban Management, 6, pp. 66-79, 2017.

[26] Căilean, D. \& Teodosiu, C., An assessment of the Romanian solid waste management system based on sustainable development indicators. Sustainable Production and Consumption, 8, pp. 45-56, 2016.

[27] Rigamonti, L., Sterpi, I. \& Grosso M., Integrated municipal waste management systems: An indicator to assess their environmental and economic sustainability. Ecological Indicators, 60, pp. 1-7, 2016.

[28] Zaman, A.U., Identification of key assessment indicators of the zero waste management systems. Ecological Indicators, 36, pp. 682-693, 2014.

[29] Apostol, T., Cemin, A., Panaitescu, V., Rada, E.C. \& Ragazzi, M., Una proposta per un indicatore di efficienza della gestione integrata dei rifiuti. RS-ORifiuti Solidi, 19, pp. 213-220, 2005.

[30] Huysman, S., De Schaepmeester, J., Ragaert, K., Dewulfm J. \& De Meesterm S., Performance indicators for a circular economy: A case study on post-industrial plastic waste. Resources Conservation \& Recycling, 120, pp. 46-54, 2017.

[31] Cifrian, E., Galan, B., Andres, A. \& Viguri, J.R., Material flow indicators and carbon footprint for MSW management analysis and application at regional level, Cantabria, Spain. Resources Conservation \& Recycling, 68, pp. 54-66, 2012.

[32] Gu, F., Zhang, W., Guo, J. \& Hall, P., Exploring "Internet+Recycling": Mass balance and life cycle assessment of a waste management system associated with a mobile application. Science of the Total Environment, 649, pp. 172-185, 2019. 
[33] Rada, E.C., Zatelli, C., Cioca, L.I. \& Torretta, V., Selective collection quality index for municipal solid waste management. Sustainability, 10, pp. 1-17, 2018.

[34] Esmaeilizadeh, S., Shaghaghi, A. \& Taghipour, H., Key informants' perspectives on the challenges of municipal solid waste management in Iran: A mixed method study. Journal of Material Cycles and Waste Management, 22, pp. 1284-1298, 2020.

[35] Liu, J., Yu, S. \& Shang, Y., Toward separation at source: Evolution of municipal solid waste management in China. Frontiers in Environmental Science and Engineering, 14(36), 2020.

[36] Xiao, S., Dong, H., Geng, Y., Tian, X., Liu, C. \& Li, H., Policy impacts on municipal solid waste management in Shanghai: A system dynamics model analysis. Journal of Cleaner Production, 262, 121366, 2020.

[37] Nagpure, A.S., Assessment of quantity and composition of illegal dumped municipal solid waste (MSW) in Delhi. Resources Conservation and Recycling, 141, pp. 54-60, 2019.

[38] Vaverková, M.D., Adamcová, D., Winkler, J., Koda, E., Petrželová, L. \& Maxianová, A., Alternative method of composting on a reclaimed municipal waste landfill in accordance with the circular economy: Benefits and risks. Science of the Total Environment, 723, 137971, 2020.

[39] Wang, D., Tang, Y.-T., Long, G., Higgitt, D., He, J. \& Robinson, D., Future improvements on performance of an EU landfill directive driven municipal solid waste management for a city in England. Waste Management, 102, pp. 452-463, 2020.

[40] Iyamu, H.O., Anda, M. \& Ho, G., A review of municipal solid waste management in the BRIC and high-income countries: A thematic framework for low-income countries. Habitat International, 95, 102097, 2020.

[41] Fedotkina, O., Gorbashko, E. \& Vatolkina, N., Circular economy in Russia: Drivers and barriers for waste management development. Sustainability, 11, 5837, 2019.

[42] Zhang, H., Wen, Z. \& Chen, Y., Environment and economic feasibility of municipal solid waste central sorting strategy: A case study in Beijing. Frontiers in Environmental Science and Engineering, 10, 10, 2016.

[43] Tulokhonova, A. \& Ulanova, O., Assessment of municipal solid waste management scenarios in Irkutsk (Russia) using a life cycle assessment-integrated waste management model. Waste Management and Research, 31, pp. 475-484, 2013.

[44] Polygalov, S., Ilinykh, G., Sliusar, N., Korotaev, V. \& Rukavishnikova, I., Challenges and opportunities for energy recovery from municipal solid waste in the Russian Federation. WIT Transactions on Ecology and the Environment, vol. 222, WIT Press: Southampton and Boston, pp. 131-143, 2019.

[45] Industrial development strategies for the processing, treatment and disposal of industrial waste and MSW for the period up to 2030, Russian government Order No 84-r. http://docs.cntd.ru/document/556353696. Accessed on: 18 Dec. 2020.

[46] Kiselev, A., Magaril, E., Rada, E.C., Energy and sustainability assessment of municipal wastewater treatment under circular economy paradigm. WIT Transactions on Ecology and the Environment, vol. 237, WIT Press: Southampton and Boston, pp. 109-120, 2019.

[47] Paukov, A., Magaril, R. \& Magaril, E., An investigation of the feasibility of the organic municipal solid waste processing by coking. Sustainability, 11, 389, 2019.

[48] Plastinina, I., Teslyuk, L., Dukmasova, N. \& Pikalova, E., Implementation of circular economy principles in regional solid municipal solid waste management: The case of Sverdlovskaya oblast (Russian Federation). Resources, 8, 90, 2019. 
218 The Sustainable City XV

[49] Rada, E.C., Magaril, M.R., Schiavon, M., Karaeva, A., Chashchin, M. \& Torretta, V., MSW management in universities: Sharing best practices. Sustainability, 12, 5084, 2020. 